\title{
Past, present and future of respiratory research: A survey of Canadian health care professionals
}

\author{
Mika Laura Nonoyama RRT PhD ${ }^{1}$, Sunita Mathur PT PhD², Rosemary Herbert BN MN PhD ${ }^{3}$, \\ Heather Jenkins BMR (PT) MSc${ }^{4}$, Michelle Lobchuk BN MN PhD ${ }^{5}$, Michelle McEvoy BA ${ }^{6}$
}

ML Nonoyama, S Mathur, R Herbert, H Jenkins, M Lobchuk, M McEvoy. Past, present and future of respiratory research: A survey of Canadian health care professionals. Can Respir J 2015;22(5):275-281.

BACKGROUND: The Canadian Respiratory Health Professionals (CRHP) is the multidisciplinary health care professional group of the Canadian Lung Association. Although the CRHP has a growing number of highly qualified researchers, the landscape of their research in Canada has not been described.

OBJECTIVES: To describe the level of respiratory research engagement; identify barriers and facilitators to research engagement; describe the experience and interest in developing research skills; and identify priority areas of future respiratory research among health care professionals.

METHODS: An online survey of CRHP members was used to collect demographic information; barriers and facilitators to conducting research; future directions in respiratory research; and research funding and mentorship. Experience with and interest in 'upskilling' research skills were also evaluated. RESULTS: A total of 119 surveys were completed (22\% response rate), of which 69 (58\%) respondents were engaged in respiratory research. Reasons for not being involved in respiratory research were lack of mentorship, support and funding. The top research areas were chronic obstructive pulmonary disease $(74 \%)$ and asthma (41\%). The top facilitators for research engagement were amount of funding (29\%) and mentorship (28\%). Respondents in research positions rated their experience in research skills as high; those in nonresearch positions as low. However, both groups expressed interest in improving their research skills.

CONCLUSIONS: Areas of development, such as research skills, greater funding opportunities and mentorship to increase the research capacity of health care professionals in respiratory health were identified. Health professional researchers have an important role in the national respiratory research strategy to increase interdisciplinary engagement and build collaborative teams.

Key Words: Health care professionals; Research capacity; Research priorities; Respiratory; Survey

\section{Le passé, le présent et l'avenir de la recherche en santé respiratoire : une enquête auprès de professionnels de la santé canadiens}

HISTORIQUE : Les Professionnels canadiens en santé respiratoire (PCSR) désignent le groupe de professionnels de la santé multidisciplinaires de l'Association pulmonaire du Canada. Même si les PCSR sont formés d'un nombre croissant de chercheurs hautement qualifiés, le paysage de cette recherche au Canada n'a jamais été décrit.

OBJECTIFS : Décrire l'engagement en recherche respiratoire, déterminer les obstacles et les incitatifs à cet engagement, décrire l'expérience et l'intérêt à acquérir des habiletés de recherche et établir les priorités des futures recherches en santé respiratoire chez les professionnels de la santé. MÉTHODOLOGIE : Les chercheurs ont utilisé un sondage virtuel auprès des membres des PCSR pour colliger des renseignements démographiques, les obstacles et les incitatifs à la recherche, les futures orientations de la recherche en santé respiratoire, le financement de la recherche et le mentorat. Ils ont également évalué l'expérience et l'intérêt à accroître les habiletés en recherche.

RÉSULTATS : Au total, 119 répondants ont participé (taux de réponse de $22 \%)$, dont 69 (58\%) faisaient de la recherche en santé respiratoire. Les raisons de ne pas en faire étaient l'absence de mentorat, de soutien et de financement. La maladie pulmonaire obstructive chronique $(74 \%)$ et l'asthme (41\%) étaient les principaux secteurs de la recherche. La quantité de financement $(29 \%)$ et le mentorat (28\%) étaient les principaux incitatifs à faire de la recherche. Les répondants qui faisaient de la recherche ont classé leurs habiletés de recherche comme élevées. Ceux qui n'en faisaient pas les évaluaient comme faibles. Cependant, les deux groupes désiraient améliorer leurs habiletés.

CONCLUSIONS : Les chercheurs ont déterminé que les habiletés de recherche, le nombre de possibilités de financement et le mentorat pour accroître la capacité de recherche des professionnels en santé respiratoire étaient les secteurs à améliorer. Les professionnels de la santé qui font de la recherche ont un rôle important à jouer dans la stratégie de recherche en santé respiratoire pour accroître la mobilisation interdisciplinaire et former des équipes coopératives.

The CRHP engages health care professionals in knowledge generation (research) and knowledge translation (education and dissemination) by providing annual grant and fellowship funding competitions, and engaging members in research strategies and the annual conference of the CLA. Research conducted by nonphysician, health care professionals has evolved over the past few decades and there has been an increased focus on evidence-based practice (5). Many of the health professional programs have implemented postgraduate degrees (Master's and Doctoral programs) (6), leading to growing numbers of highly qualified independent health care professional investigators in the field of respiratory health.

Research is necessary to ensure that professional education and practice is driven by a strong evidence base (5). Several large surveys have described research engagement by health professionals functioning as independent investigators as well as those within research networks or macists and other health professionals working in the respiratory field.

${ }^{1}$ Faculty of Health Sciences, University of Ontario Institute of Technology, Oshawa; ${ }^{2}$ Department of Physical Therapy, University of Toronto, Toronto, Ontario; ${ }^{3}$ School of Nursing, University of Prince Edward Island, Charlottetown, Prince Edward Island; ${ }^{4}$ Winnipeg Children's Hospital, Child Health Physiotherapy; ${ }^{5}$ Faculty of Health Sciences, College of Nursing, University of Manitoba, Winnipeg, Manitoba;

${ }^{6}$ Manager, National Research Programs, Canadian Lung Association

Correspondence: Dr Mika Laura Nonoyama, Faculty of Health Sciences, University of Ontario Institute of Technology, 2000 Simcoe Street North,

Toronto, Ontario L1H 7K4. Telephone 905-721-8668 ext 5329, e-mail mika.nonoyama@uoit.ca 
TABLE 1

Demographic characteristics of respondents $(n=119)$ n (\%)

CRHP member duration, years

$<5$

5-10

$46(39)$

$11-20$

$16(13)$

$>20$

$8(7)$

Profession

Respiratory therapist

Nurse

Physical therapist

$23(19)$

Pharmacy

Kinesiology or clinical exercise physiologist

Occupational therapist

Clinical research coordinator

Other*

$36(30)$

$30(25)$

Diploma

Masters (thesis based)

$19(16)$

$\mathrm{PhD}$

$16(13)$

Masters (entry-level)

$11(9)$

Certified Respiratory Educator

1 (1)

Primary appointment ${ }^{\dagger}$

Clinician

$48(40)$

Manager or administrative role

$23(19)$

Clinical educator

$18(15)$

Postsecondary school tenure track

$14(12)$

Graduate student

4 (3)

Postsecondary school nontenure track

Clinical scientist

2 (2)

Clinical research coordinator

$2(2)$

Technologist

$2(2)$

1 (1)

Clinician scientist

$1(1)$

Work setting ${ }^{\ddagger}$

Acute care hospital

Academic institute

$36(30)$

Community setting

$36(30)$

Primary care setting

$17(14)$

Rehabilitation institute

15 (13)

Not-for-profit organization

$10(8)$

Government

5 (2)

Industry

4 (3)

Other

1 (1)

Province§

Ontario

Alberta

Quebec

$12(10)$

Manitoba

$6(5)$

Saskatchewan

Nova Scotia

British Columbia

$3(3)$

New Brunswick

$1(1)$

Newfoundland

2 (2)

*Dietitian, social work ( $n=2$ also a certified respiratory educator, pulmonary function technologist); ${ }_{n}=1$ did not answer; ${ }^{\ddagger}$ Respondents checked "all that apply"; $\S_{n}=2$ did not answer. CRHP Canadian Respiratory Health Professionals collaborations $(7-10)$, mentoring or trainee programs $(11,12)$, practice or primary care or ambulatory care-based research (13-15), and clinical research (16). However there are no Canadian studies describing the involvement and future needs of health care professionals in the area of respiratory health research. Describing current levels of experience, engagement and future priorities in respiratory research in Canada will help move strategies such as the NRRS in a direction that best supports all investigators across health disciplines in the conduct of their research.

The objectives of the present study were to determine the current level of engagement in respiratory research; identify barriers and facilitators in respiratory research engagement; describe the experience and interest in developing research skills; and identify priority areas of future respiratory research as described by respiratory health professionals in the CRHP.

\section{METHODS}

Survey process

CRHP members were provided a link to a FluidSurveys ${ }^{\mathrm{TM}}$ electronic survey via e-mail and the monthly e-newsletter (English and French), which was sent by a staff member at the CLA who was not a study investigator. A modified Dillman approach (17) was used to optimize response rate by sending a reminder e-mail with the survey link at two and four weeks after the initial contact, by the same staff member. Respondents provided consent on the first page of the electronic survey. The study was approved by the University of Toronto Clinical Research Ethics Board (Toronto, Ontario).

\section{Questionnaire}

The questionnaire developed by the investigators (MN and SM) consisted of closed-ended questions and took approximately $15 \mathrm{~min}$ to complete (Appendix [go to www.pulsus.com]). Open-ended questions were used to collect additional comments only. The following data were collected: demographics, work-related knowledge of CRHP research funding mechanisms, barriers and facilitators to conducting research, areas of current respiratory research, future directions for respiratory research and experience with research mentorship. The response options for disease groups, research disciplines (eg, genetics, rehabilitation, health economics), genres (eg, clinical science, population health and knowledge translation) and methodology (eg, mixed methods, quantitative and qualitative) were developed using terminology from the Canadian Institutes of Health Research Grants \& Awards Guide and CLA research programs. Experience with and interest in learning additional skills or "upskilling" 10 specific research skills were assessed using a simple survey and visually presented using a research spider graph $(7,18)$. Participants were asked to rate their experience and interest in upskilling on a five-point Likert scale $(1=$ no, $2=$ little, $3=$ some, $4=$ moderately, $5=$ very $)$. The authors pilot tested this questionnaire with four health care professionals for content, clarity and flow. Although no data were collected or stored from the pilot exercise, participants' feedback was incorporated into the final questionnaire.

\section{Statistical analysis}

Data from the questionnaire were exported into Excel 2010 (Microsoft Corporation, USA) and SPSS version 20 (IBM Corporation, USA). Descriptive statistics (frequency counts, percentages) were used to capture demographic data for the total study sample, as well as research skills reported by participants engaged in respiratory research. Plots were used to examine pattern distributions across different categories. Only completed questionnaires were included in the analyses. Three pairwise comparisons were performed on the following questions: "are you familiar with" versus "have you applied for" the various CRHP awards (McNemar test); which funding agencies did you "apply for" versus "successfully obtain" (McNemar test); and the individual's "experience with" versus "interest in upskilling" research skills (Wilcoxon test). An independent $t$ test was also performed to compare the number of funding applications to any funding agency, submitted and successful, according to respondents in research positions versus nonresearch positions. 
TABLE 2

Research characteristics of respondents engaged in research $(n=69)$

\begin{tabular}{|c|c|}
\hline & $\mathbf{n}(\%)$ \\
\hline \multicolumn{2}{|l|}{ Duration engaged in respiratory research, years } \\
\hline$<1$ & $16(23)$ \\
\hline $1-5$ & $20(29)$ \\
\hline $5-10$ & $17(25)$ \\
\hline $10-15$ & $8(12)$ \\
\hline$>15$ & $11(16)$ \\
\hline \multicolumn{2}{|l|}{ Research genre $^{*}$} \\
\hline Clinical science & $32(46)$ \\
\hline Program evaluation & $23(33)$ \\
\hline Knowledge translation & $22(32)$ \\
\hline Population health & $20(29)$ \\
\hline Clinical trials & $20(29)$ \\
\hline Policy & $6(9)$ \\
\hline Basic science & $2(3)$ \\
\hline \multicolumn{2}{|l|}{ Research discipline* } \\
\hline Patient education & $33(48)$ \\
\hline Rehabilitation & $28(41)$ \\
\hline Preventive health/wellness & $22(32)$ \\
\hline Knowledge translation & $20(29)$ \\
\hline Exercise & $19(28)$ \\
\hline Lung physiology/pathophysiology & $13(19)$ \\
\hline Psychosocial health & $12(17)$ \\
\hline Pharmaceuticals & $10(14)$ \\
\hline Technology assessment & $10(14)$ \\
\hline Health care policy & $6(9)$ \\
\hline Complementary and alternative medicine & $5(7)$ \\
\hline Bioengineering/medical devices & $5(7)$ \\
\hline Other $^{\dagger}$ & $11(15)$ \\
\hline \multicolumn{2}{|l|}{ Research topic ${ }^{*}$} \\
\hline Chronic obstructive pulmonary disease & $51(74)$ \\
\hline Asthma & $28(41)$ \\
\hline Prevention of lung disease (eg, smoking cessation) & $15(22)$ \\
\hline Long-term mechanical ventilation & $13(19)$ \\
\hline Critical care & $11(16)$ \\
\hline Pulmonary fibrosis & $9(13)$ \\
\hline Cystic fibrosis & $8(12)$ \\
\hline Lung cancer & $7(10)$ \\
\hline Lung transplant & $5(7)$ \\
\hline Other $\ddagger$ & $12(20)$ \\
\hline \multicolumn{2}{|l|}{ Research methodology } \\
\hline Mixed methods & $32(46)$ \\
\hline Quantitative & $20(29)$ \\
\hline Qualitative & $16(23)$ \\
\hline Other (not specified) & $1(1)$ \\
\hline \multicolumn{2}{|l|}{ Research population age group* } \\
\hline Adult (17-64 years) & $50(72)$ \\
\hline Seniors (>65 years) & $44(64)$ \\
\hline Pediatric ( $0-17$ years) & $18(26)$ \\
\hline Not applicable & $6(9)$ \\
\hline \multicolumn{2}{|c|}{ Research funding (all sources) supporting respiratory research (PI or co-I) } \\
\hline$<\$ 10,000$ & $37(54)$ \\
\hline$\$ 10,000$ to $\$ 49,999$ & $7(10)$ \\
\hline$\$ 50,000$ to $\$ 99,999$ & $3(4)$ \\
\hline$\$ 100,000$ to $\$ 499,999$ & $5(7)$ \\
\hline$\$ 500,000$ to $\$ 1$ million & $4(6)$ \\
\hline$>\$ 1$ million & $4(6)$ \\
\hline
\end{tabular}

Continued in next column
TABLE 2 - CONTINUED

Research characteristics of respondents engaged in research $(n=69)$

\begin{tabular}{lc}
\hline & $\mathbf{n}(\%)$ \\
\hline Journals published & \\
Respiratory, cardiac or sleep & $25(36)$ \\
Profession specific & $19(28)$ \\
Open access & $13(19)$ \\
Paediatric & $3(4)$ \\
Other & $7(10)$ \\
Quality of mentor & \\
Excellent & $18(15)$ \\
Very Good & $10(8)$ \\
Good & $13(11)$ \\
Fair & $1(1)$ \\
Poor & $5(4)$ \\
\hline
\end{tabular}

*Respondents checked "all that apply"; ${ }^{\dagger}$ Health economics, cell or molecular biology, epidemiology/data analysis, genetics, biostatistics, professional practice; ¥Sleep, artificial airways, pediatric lung disease, health technology assessment, tuberculosis, stroke; $\S_{n}=9$ did not answer; ${ }^{\top}$ Health education, medicine, population health, transplant, aerosol science, visualized journal, rural health; ${ }^{* *} n=22$ did not answer or had no mentor. co-l Co-investigator; PI Primary investigator

\section{RESULTS}

Demographic characteristics (Table 1)

Of 530 CRHP members, 141 started the survey resulting in a $22 \%$ response rate. Of these, 119 surveys were complete, 11 were partially complete and 11 provided no information. As shown in Table 1, 95 participants ( $80 \%$ ) had been CRHP members for $\leq 10$ years. Most respondents were from Ontario, Alberta and Quebec, which reflects the regional distribution of CRHP membership. The majority of respondents were respiratory therapists, nurses or physiotherapists and had entry-level Master's, Bachelor's or Diploma level training, with only 35 respondents with thesis-based $\mathrm{MSc}$ or $\mathrm{PhD}$. Forty percent stated they were employed as a clinician. There was representation across work settings including acute care hospitals, community settings and academic institutions. Ninety-two respondents (77\%) were not in a research-related position (clinician, clinical educator, manager or other administrative role, technologist, retired); 26 respondents (22\%) were in a research-related position (university/college faculty, clinical scientist, graduate student, postdoctoral fellow, research coordinator). This is in contrast with the general CRHP membership in which $47 \%$ indicate some role in research and $52 \%$ of members indicate no role in research (clinical, teaching and/or administration only).

Characteristics of research experience

The characteristics of research experience and areas of study are described in Table 2. Thirty-nine percent of the respondents were currently engaged in respiratory research and an additional 19\% reported previous research involvement. Seventy-seven percent had been engaged in research for $<10$ years. The most common research genres included clinical science, program evaluation and knowledge translation. Individual respondents indicated they were engaged in several research disciplines, the most common being patient education, rehabilitation, and preventive health and wellness. There was a wide range of research topics being studied, with chronic obstructive pulmonary disease (COPD) (74\%) and asthma (41\%) being the most common. The majority of respondents used mixed-methods research methodology.

Involvement in research activities

In the present survey, respondents were asked about publishing research in peer-reviewed journals; awareness of grant funding opportunities through the CRHP; and experience and success in obtaining peer-reviewed funding. Research career productivity, measured by the median (range) of total peer-reviewed respiratory articles authored or 


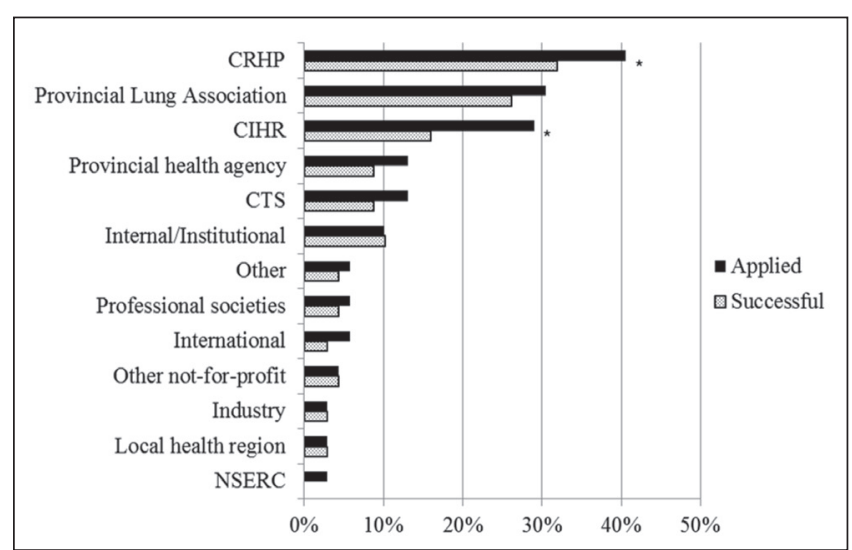

Figure 1) Research funding applied for/successfully received ( $n=69)$. Respondents checked 'all that apply'; $* P<0.05$. CIHR Canadian Institutes of Health Research; CRHP Canadian Respiratory Health Professionals; CTS Canadian Thoracic Society; NSERC Natural Sciences and Engineering Research Council of Canada

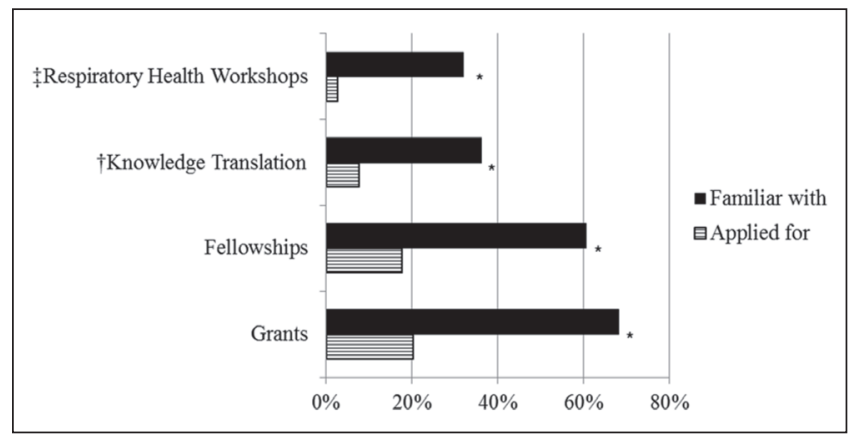

Figure 2) Canadian Respiratory Health Professionals awards: Familiarity with and applied for ( $n=119) ;{ }^{\ddagger} n=3$ did not answer (both questions); ${ }^{\dagger} n=2$ did not answer "familiar with?" and n=3 "applied for?" questions; *McNemar test, $P<0.0001$

co-authored, was one (zero to 51) articles. Articles were mainly published in respiratory, cardiac, sleep or profession-specific journals, with a minority in open access, pediatric or other journals (Table 2).

Respondents applied for research funds from various sources including the CRHP awards (41\%), provincial Lung Associations (30\%) and the Canadian Institutes of Health Research (29\%) (Figure 1). Career research funding (estimated as the "total funding received" at the time of the survey) secured as a primary (PI) or coinvestigator (co-I) was low; the majority $(54 \%)$ of respondents secured $<\$ 10,000$ (Table 2). The proportion of any funding success as a PI or co-I $(n=85)$ was less than the proportion of career-to-date funding submissions $(\mathrm{n}=115)$. Eighty-one percent of participants in research positions had at least one successful application as PI or co-I, while only $23 \%$ of those in non-esearch positions had a successful submission. The number of participants in research positions with no funding success was five of 26 (19\%). In comparison, 71 of 92 (77\%) in nonresearch positions reported no funding success. There were significant differences between success and application for Canadian Institutes of Health Research awards (20 [29\%] applied; 11 [16\%] successful, $\mathrm{P}=0.004)$ and CRHP awards (28 [41\%] applied; 22 [32\%] successful, $\mathrm{P}=0.03$ ) (Figure 1). With respect to the different CRHP awards, the majority of respondents were familiar with grants $(68 \%)$ and fellowships $(61 \%)$ but significantly fewer had applied for them (20\% and $18 \%$, respectively). The majority of respondents were not familiar with or unsure about the knowledge translation (62\%) or the respiratory health workshop (62\%) awards; consequently, respondents had not applied for them (Figure 2). The mean ( \pm SD) number of CRHP funding applications submitted by respondents in research positions was $3.0 \pm 1.9$ compared with $0.40 \pm 0.8$ applications

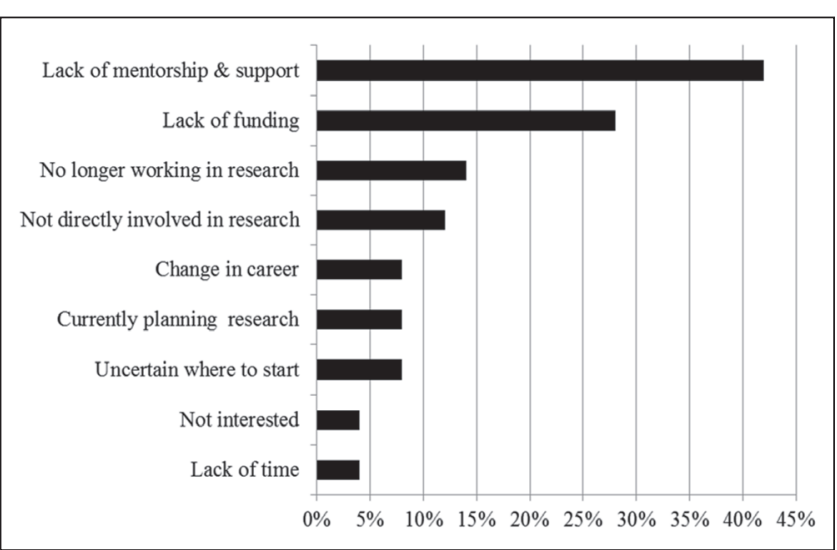

Figure 3) Reasons respondents were not engaged in respiratory research $(n=64)$

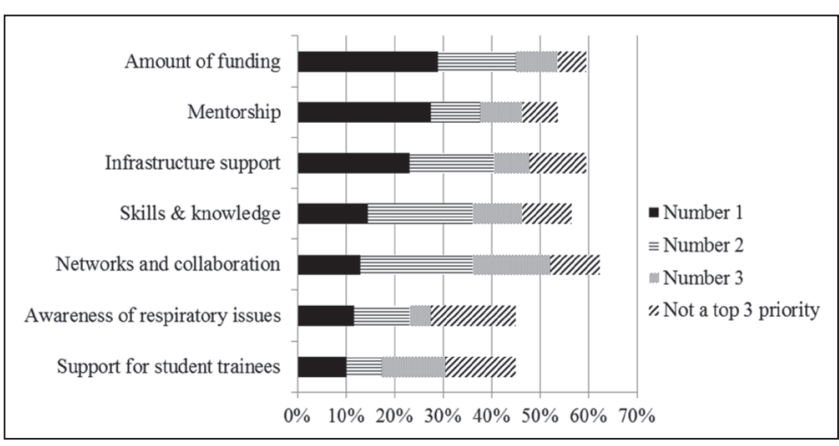

Figure 4) Facilitators for engaging in respiratory research

from those in nonresearch positions $(\mathrm{P}<0.0001)$. Similarly, the mean number of funds successfully obtained by respondents in research positions was greater $(2.0 \pm 1.4)$ than those in nonresearch positions $(0.35 \pm 0.7 ; \mathrm{P}<0.0001)$.

The primary reasons for not being involved in respiratory research were reported only by those in nonresearch positions and included lack of mentorship and support (42\%) and lack of funding (28\%). The least common reasons (for respondents in both research and nonresearch positions) were lack of interest (4\%) or time (4\%) (Figure 3). The median (interquartile range) percentage of time secured for research activities was also low at $10 \%$ ( $1 \%$ to $40 \%$ ); the majority (69\%) with $<30 \%$ secured time.

\section{Research barriers, facilitators and mentorship}

The top facilitating factors (rated on importance) for engaging in research were the amount of funding (29\%), mentorship (28\%) and infrastructure support (23\%) (Figure 4). The top barriers also included the amount of funding (41\%), the lack of infrastructure support (29\%), and a lack of skills and knowledge on how to engage in research (14\%) (Figure 5). The most important future need was more funding (35\%) followed by mentorship programs (19\%) (Figure 6). Least important future needs included longer duration of funding (29\%), fellowship support $(16 \%)$ and respiratory research advocacy $(16 \%)$.

When asked specifically about mentorship, 38 (55\%) reported that they had an informal or formal research mentor; 23 (33\%) did not have mentor, and eight (12\%) did not respond. While 22 (32\%) respondents did not respond about the quality of their mentor, 10 (14\%) reported their mentor as being very good and $18(26 \%)$ stated their mentor was excellent (Table 2). Finally, 31 (45\%) stated that they would benefit from a mentor outside their workplace, four $(6 \%)$ would not and 19 (28\%) were unsure.

\section{Research priorities}

Respondents were asked to rank their top three respiratory research priorities from a list of 14 areas (shown in Figure 2). The highest ranking 
TABLE 3

Research skills of respondents in research and nonresearch positions - experience with and interest in upskilling (n=119)

\begin{tabular}{|c|c|c|c|c|c|c|c|}
\hline \multirow[b]{2}{*}{ Research skill } & \multicolumn{3}{|c|}{ Experience } & \multicolumn{3}{|c|}{ Interest in up-skilling } & \multirow[b]{2}{*}{$\mathbf{P}^{*}$} \\
\hline & $\mathbf{n}$ & Median (IQR) & Mean \pm SD & $\mathbf{n}$ & Median (IQR) & Mean \pm SD & \\
\hline Writing research protocol & 111 & $2.0(1.0-4.0)$ & $2.4 \pm 1.5$ & 109 & $3.0(2.0-4.0)$ & $2.9 \pm 1.4$ & 0.0001 \\
\hline Apply for research funding & 111 & $1.0(1.0-3.0)$ & $2.2 \pm 1.4$ & 108 & $3.0(2.0-4.0)$ & $2.9 \pm 1.4$ & $<0.0001$ \\
\hline Finding relevant literature & 111 & $4.0(2.0-4.0)$ & $3.4 \pm 1.3$ & 110 & $3.0(3.0-4.0)$ & $3.4 \pm 1.2$ & 0.95 \\
\hline Critically reviewing literature & 111 & $3.0(2.0-4.0)$ & $3.2 \pm 1.4$ & 110 & $3.0(3.0-4.0)$ & $3.4 \pm 1.2$ & 0.15 \\
\hline Using quantitative methods & 110 & $2.5(1.0-4.0)$ & $2.6 \pm 1.4$ & 110 & $3.0(2.0-4.0)$ & $3.2 \pm 1.4$ & 0.0001 \\
\hline Writing and presenting reports & 111 & $2.0(1.0-4.0)$ & $2.5 \pm 1.5$ & 110 & $3.0(2.0-4.0)$ & $3.1 \pm 1.4$ & 0.0002 \\
\hline Publishing research & 111 & $1.0(1.0-3.0)$ & $2.1 \pm 1.4$ & 110 & $3.0(2.0-4.0)$ & $3.0 \pm 1.4$ & $<0.0001$ \\
\hline Using qualitative methods & 111 & $2.0(1.0-3.0)$ & $2.2 \pm 1.3$ & 111 & $3.0(2.0-4.0)$ & $3.0 \pm 1.3$ & $<0.0001$ \\
\hline
\end{tabular}

Survey scale: $1.0=$ no; 2.0 = little; $3.0=$ some; $4.0=$ moderate; $5.0=$ very experienced/interested. Where total $n$ is not 119 , participants did not answer. ${ }^{*}$ Wilcoxon test. IQR Interquartile range

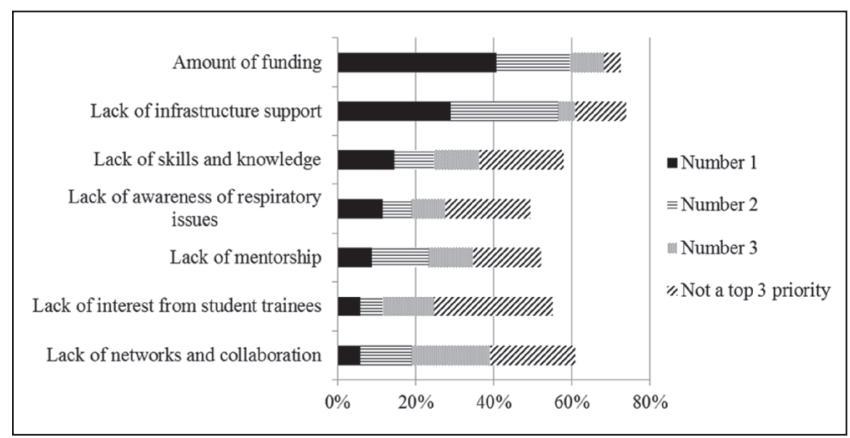

Figure 5) Barriers for engaging in respiratory research

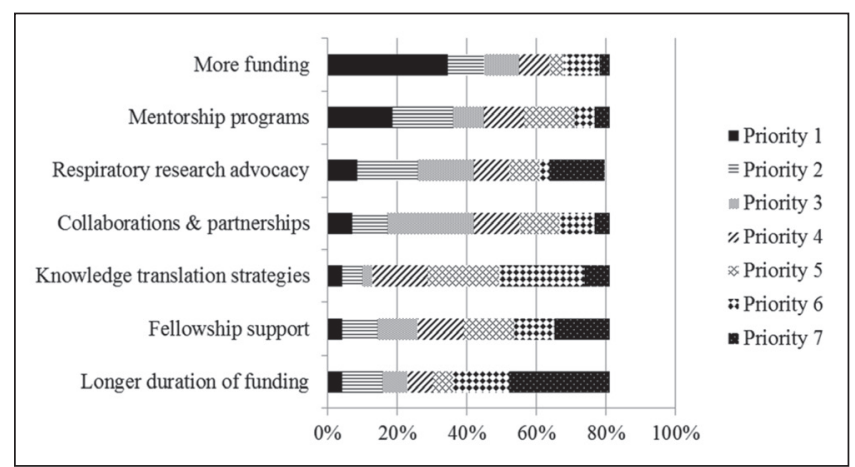

Figure 6) Future needs of respiratory research

areas (in both the research and nonresearch groups) were chronic disease management $(43 \%)$, aging $(n=11,16 \%)$, outpatient and community care (16\%), and acute care (14\%) (Figure 7).

Research skills: experience and interest in upskilling

One hundred nineteen respondents rated their experience with research skills as low: they chose 'no' experience (rating of 1.0) to 'some' experience (rating of 3.0) for nine of the 10 listed research skills. Fifty percent of the respondents provided the lowest ratings (a median score of 1.0) on applying for research funding and publishing research. Finding relevant literature was the only research skill where respondents (49\%) rated their experience as 'moderate' to 'very experienced' (median score $=4.0$ ). Respondents had reported a greater interest in improving the majority of their research skills compared with their level of research experience (Table 3, Figure 8). The median score of 3.0 indicated 'some' interest in upskilling in all 10 research skills as reported by 119 respondents. Respondents in research positions $(n=26)$ scored higher in all 10 research skills compared with those in nonresearch positions $(n=92)$. Similarly, respondents in

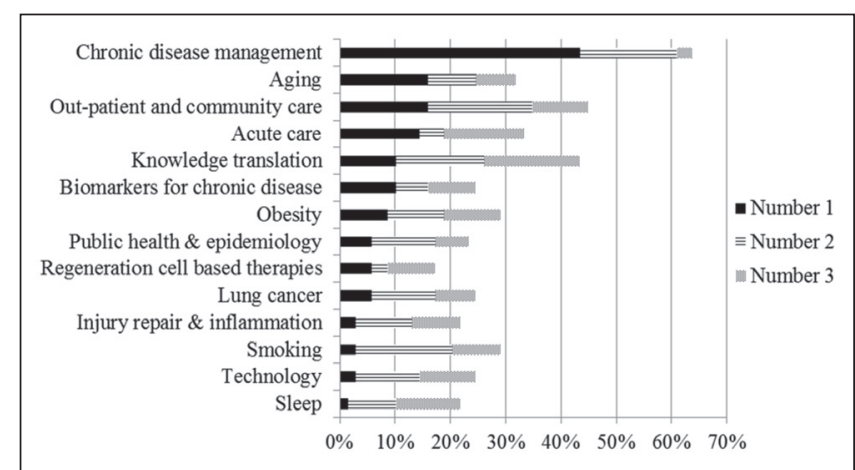

Figure 7) Topic priorities in respiratory research

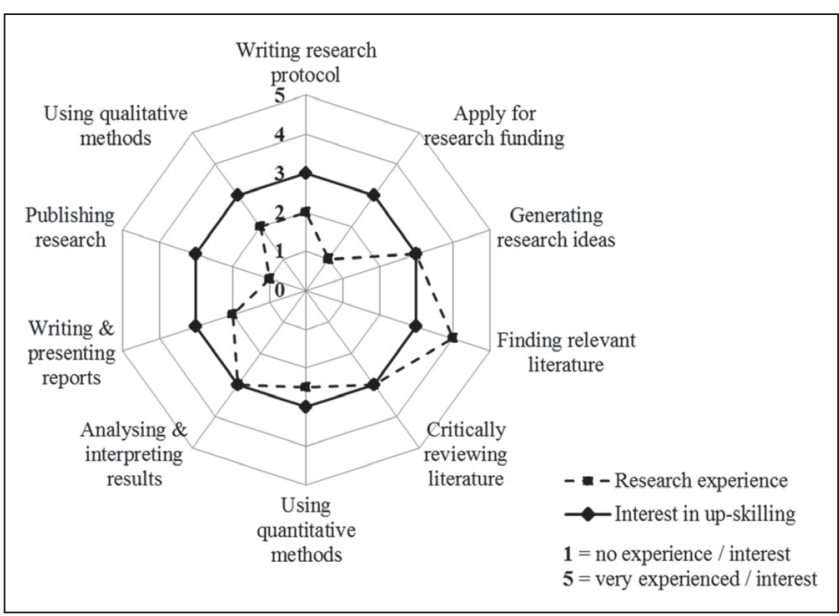

Figure 8) Experience and interest in upskilling research spider (median); $n=119$ (see Table 3 for numbers of those who did not answer). Participants were asked to rate their experience and interest in upskilling on a five-point Likert scale from 1 (no experience/interest) to 5 (high experience/interest). The interest in upskilling (solid line) is the same or higher in nine of the 10 skills compared with the level of research experience (dotted line). The only skill that respondents rated their experience higher than their interest in upskilling it was 'finding the literature'

research positions had higher interest in improving all skills except 'finding the relevant literature' where both groups had the same median score (Figures 9 and 10).

\section{DISCUSSION}

The present paper describes the involvement of Canadian health professionals who are CRHP members in respiratory research, along with the 


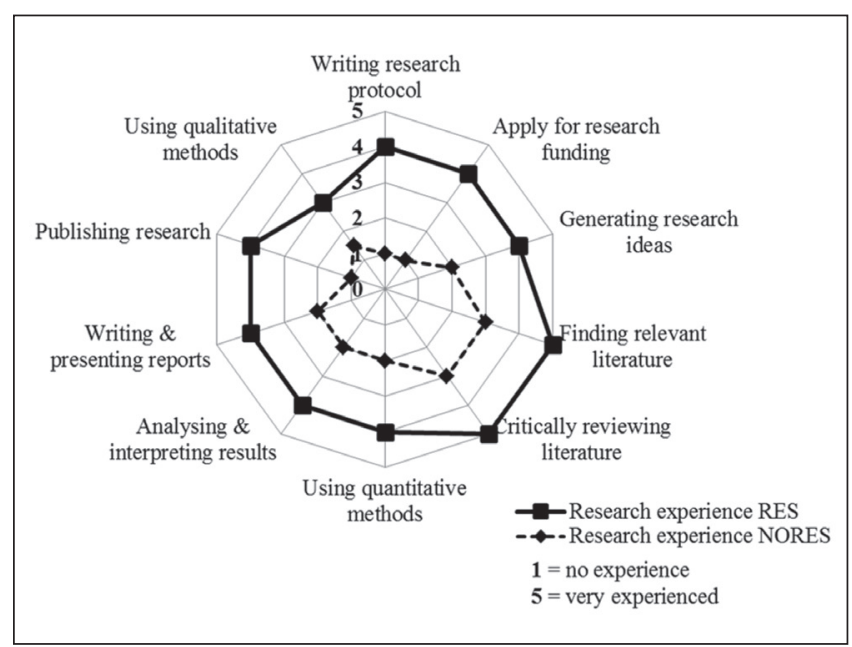

Figure 9) Experience research spider (median): Research (RES) versus Non-Research Position (NORES). Participants were asked to rate their experience on a five-point Likert scale from 1 (no experience) to 5 (high experience). The solid line represents those in research positions $(n=80)$ while the dotted line those in nonresearch positions $(n=23)$

barriers and facilitators for engagement. Fifty-eight percent of survey respondents were engaged in respiratory research. From the respondents who were not involved in research, their reasons were lack of mentorship, support and funding. Respondents in research positions rated their experience with research skills high while those in nonresearch positions rated them low. However, respondents in both research and nonresearch positions expressed greater interest in improving their research skills. This information can be used to promote greater engagement of health professionals within the NRRS or similar research initiatives of the CLA that focus on providing education, mentorship and funding support. The NRRS aims to expand and improve Canada's research capacity in lung health through three pillars: a National Training Program to build research capacity; a National Grant Program to support research projects; and an Integrated Knowledge Translation Strategy (4). With current changes in the research funding climate, collaborative research teams crossing all three of these pillars are needed.

\section{Pillar 1: Building respiratory research capacity}

Before CRHP members can apply for research grants, further research training and skills development is required, especially for those in nonresearch positions. Creating formal research positions at clinical sites for health care professionals may increase opportunities for respiratory research innovation, collaboration and output. Approximately onethird of the present study's respondents had received formal research training (thesis-based $\mathrm{MSc}$ or $\mathrm{PhD}$ ) and worked in an academic institution. Despite the level of research training, a large proportion (69\%) of respondents who were engaged in respiratory research reported $<30 \%$ of their time was secured for research. Only $17 \%$ of respondents reported $\geq 75 \%$ of their time was secured for research, which is a requirement for many research salary awards or research chair positions. One possible reason for these results was the large representation $(40 \%)$ of clinician respondents in the present study. Dedicated research time and infrastructure support for health professionals working in clinical practice is typically lower than those who hold an academic appointment at a university. Furthermore, only three respondents identified themselves as a 'clinical or clinician scientist'. In contrast, it is common for physicians to hold cross-appointments (eg, clinical scientists) with protected time because research appointments for physicians are formal arrangements at many Canadian hospitals that house a research institute. In our survey, infrastructure support was one of the top three facilitators and barriers for engaging in respiratory research. Other studies have shown that infrastructure

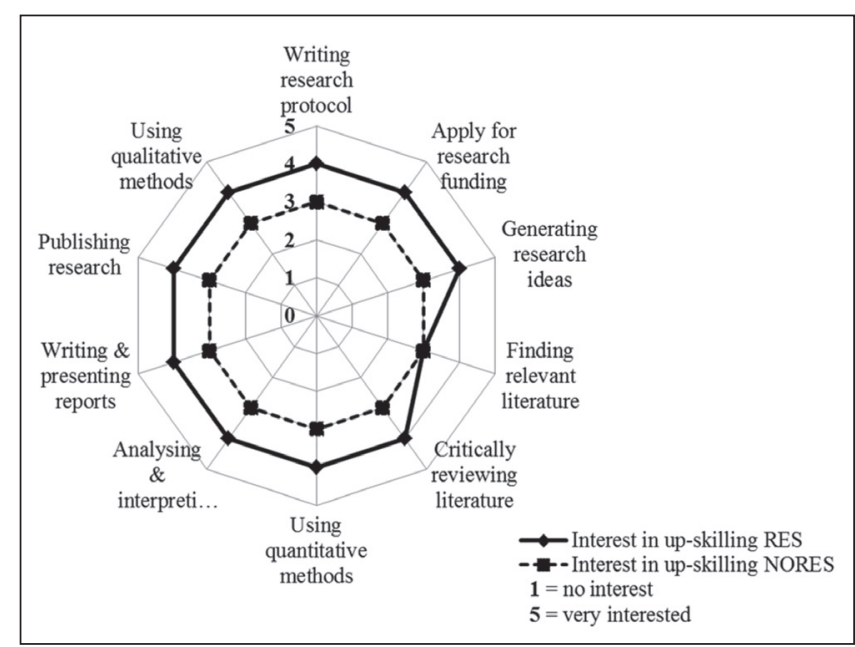

Figure 10) Interest in upskilling research spider (median): Research (RES) versus Non-Research Position (NORES). Participants were asked to rate their experience on a five-point Likert scale from 1 (no interest) to 5 (high interest). The solid line represents those in research positions $(n=80)$ while the dotted line those in nonresearch positions $(n=23)$.

(eg, presence of qualified study personnel) $(9,14)$ and secured time for research $(8,9,11,14,16)$ were important for research engagement. Developing innovative career opportunities for health professionals within hospital-based research institutes (eg, integrating clinical and research roles) is an area for future development for programs such as the NRRS.

Mentorship and training programs are essential for career development and building research capacity. Respondents reported positive mentorship experiences, but many indicated the need for research mentors outside of their workplace. The 'lack of mentorship and support' was also identified as the most common reason why respondents were not engaged in respiratory research. Respondents were interested in improving research skills where they had less experience (eg, applying for funding and publishing their work). These results are similar to a previous study on building capacity in primary care (7). Formal mentorship and training programs would help meet this need. Previous studies have shown the importance of mentorship in building research capacity and as a key factor in improving research success $(7,11,12,14,16)$. The CRHP has a national network of members that could be used to develop a formal mentorship program. Although only a small proportion would be considered experienced researchers (more than 10 years of experience), this number will grow as junior researchers gain experience and become experienced mentors themselves. NRRS's future REspiratory NAtional Scientist Core EducatioN and Training Program (RENASCENT) is an example of a formal mentorship program for research trainees and can serve to help develop and refine mentorship skills for experienced health care researchers.

With a large representation of health care clinicians, more research training at entry-level curricula could lead to greater engagement in research (if appropriate infrastructure and mentorship is available). The majority of the survey respondents were trained at the Bachelors or Diploma level. This is consistent with entry-level training for certain health care professions (eg, respiratory therapy, nursing). However, there has been a shift toward a higher entry-level education in physical therapy (moved from Bachelor's to Master's entry level across Canadian institutions between 2001 to 2012 [http://www.physiotherapyeducation. $\mathrm{ca} /$ PhysiotherapyEducation.html]) and nursing (moved from Diploma to Bachelor's since the late 1990s [http://www.cna-aiic.ca/en/becomingan-rn/education/rn-baccalaureate-education-table/]).

Pillar 2: Research funding - supporting research projects It is essential to have funding to support and build research capacity. In our survey, respondents identified funding as both the largest facilitator 
and barrier to research. 'More funding' was identified as the most common 'priority one future need' for respiratory research. The issue of funding is similar to other studies that have examined issues of engagement in research by physicians $(9,12,13)$. Increasingly competitive environments for research dollars have made even smaller grants very competitive. Over the past five years, the number of applications for CRHP grants increased from 15 in 2008/2009 to 22 in 2012/2013. In recent competitions, the number of fundable submissions exceeded those funded and the lack of funds prevented high-quality applications from being supported (ie, a shortfall of \$25,000 in 2011/2012 and $\$ 128,000$ in 2012/2013). Historically, there has also been an uneven split of research dollars allocated to the CRHP compared with the Canadian Thoracic Society national grants program (primarily physicians and nonclinical scientists). As health care professional research continues to grow and exceed its current funding envelope, the allocation of research dollars to the CRHP may need to be re-examined. The NRRS along with its current fundraising campaign (www. breathingasone.ca) pose an opportunity to raise dedicated funds specifically for respiratory research, which could increase opportunities for funding respiratory research and reduce current gaps in knowledge translation and clinical trials of nonpharmaceutical interventions.

\section{Pillar 3: Integrated knowledge translation}

An advantage of health care research is its tendency to be clinically applicable and directly translated into clinical practice (5). There is a known gap in time and knowledge between discovery and implementation into clinical practice; therefore, knowledge translation is a priority area. A large number of respondents identified knowledge translation as their research genre (32\%) and research discipline (29\%). Uptake of research findings into clinical practice can increase if interdisciplinary research teams (that develop as part of NRRS) capitalize on CRHP member expertise in knowledge translation. CRHP members can also play an important role in teaching trainees about knowledge translation strategies, which can then be incorporated into their own research.

In addition to playing an important role in knowledge translation strategies, respondents practice in respiratory research areas that are in line with front-line national respiratory health needs, where most CLA research funds have been invested (4). From 2008 to 2012, the highest amount of CLA grant funding supported COPD, asthma and

\section{REFERENCES}

1. World Health Organization. Global Status Report on

Noncommunicable Diseases 2010. 2011 ISBN 9789240686458.

2. Van Dam A, Downey AM. National Respiratory Research Strategy (NRRS). Research Matters. 2012 September.

3. O'Donnell DE. Research officially recognized as a core activity of The Lung Association. Can Respir J 2010;17:263-4.

4. Canadian Lung Association. Canadian Lung Association Research Impact Report. A 5 Year Retrospective Analysis 2008-2012. 2013.

5. Arena RA, Goldberg LR, Ingersoll CD, Larsen DS, Shelledy D. Research in the allied health professions: Why fund it? A report of the ASAHP Research Committee. J Allied Health 2011;40:161-6.

6. Phelps MR, Gerbasi F. Accreditation requirements for practice doctorates in 14 healthcare professions. AANA J 2009;77:19-26.

7. Ried K, Farmer E, Weston K. Setting directions for capacity building in primary health care: A survey of a research network. BMC Fam Pract 2006;7:8.

8. Harris J, Provan K, Johnson K, Leischow S. Drawbacks and benefits associated with inter-organizational collaboration along the discovery-development-delivery continuum: A cancer research network case study. Implement Sci 2012;7:69.

9. Paterson DL. Determining research priorities for clinician-initiated trials in infectious diseases. Med J Aust 2013;198:270-2.

10. Croughan-Minihane MS, Thom DH, Petitti DB. Research interests of physicians in two practice-based primary care research networks. West J Med 1999;170:19-24.

11. Tsen LC, Borus JF, Nadelson CC, Seely EW, Haas A, Fuhlbrigge AL. The development, implementation, and assessment of an innovative faculty mentoring leadership program. Acad Med 2012;87:1757-61. tuberculosis research. The majority of CRHP funding investments also went toward COPD (4). Similarly, most respondents in our survey reported COPD, asthma and prevention of lung disease as their main topic areas. CRHP members also prioritized chronic disease management and aging to focus efforts in respiratory research. The present study's findings on priority topics corroborate current Canadian health care needs in aging and chronic disease management $(19,20)$ and may be avenues to explore in the NRRS.

\section{Limitations}

Limitations of the present study are common with all survey methods (21). Although respondents mirrored the characteristics of CRHP members (professional and provincial representation), the response rate was low at $22 \%$ of the total membership. There was also a lower proportional response from members involved with research; only $22 \%$ of respondents had a research-related position in our survey compared with $47 \%$ of all CRHP members indicating some 'role' in research. The survey was also limited to members of the CRHP; however, there are other health care professional organizations whose members may be engaged in respiratory research and do not have co-membership with the CRHP (eg, Cardiorespiratory Division of the Canadian Physiotherapy Association; Canadian Society of Respiratory Therapists; Canadian Nursing Association).

\section{CONCLUSIONS}

Respiratory research capacity among Canadian health care professionals must increase to meet identified knowledge gaps and changing health care needs. The capacity for CRHP members to conduct research is growing. However, the majority of members still have limited time secured for research and limited infrastructure support. In addition, CRHP members feel a need to upskill across a range of research skills. The development of a mentorship program and formal research training through programs like the NRRS can assist health care professionals gain and refine their research skills, and increase their scholarly productivity. CRHP members can provide important contributions to interdisciplinary, collaborative respiratory research teams and have a key role in the development and sustainability of the NRRS.

DISCLOSURES: None to report.

12. Heckman BW, Blank MD, Peters EN, et al. Developing Tomorrow's Tobacco Scientists Today: The SRNT Trainee Network. Nicotine Tob Res 2013;15:NP.

13. Tierney WM, Oppenheimer CC, Hudson BL, et al. A National survey of primary care practice-based research networks. Ann Fam Med 2007;5:242-50.

14. Bakken S, Lantigua RA, Busacca LV, Bigger JT. Barriers, Enablers, and incentives for research participation: A report from the Ambulatory Care Research Network (ACRN). J Am Board Fam Med 2009;22:436-45.

15. Dickerson LM, Kraus C, Kuo GM, et al. Formation of a primary care pharmacist practice-based research network. Am J Health Syst Pharm 2007;64:2044-9.

16. Akerjordet K, Lode K, Severinsson E. Clinical nurses' attitudes towards research, management and organisational resources in a university hospital: Part 1. J Nurs Manag 2012;20:814-23.

17. Dilman D. Mail and Internet Surveys: The Tailored Design Method, 2nd edn. New York: John Wiley \& Sons Inc, 2000.

18. Smith H, Wright D, Morgan S, Dunleavey J. The 'Research Spider': A simple method of assessing research experience. Prim Health Care Res Dev 2002;3:139-40.

19. Canadian Institute for Health Information. Health Care in Canada, 2011: A Focus on Seniors and Aging. Ottawa, ON: CIHI, 2011.

20. Health Council of Canada. Self-management support for Canadians with chronic health conditions: A focus for primary health care. Toronto: Health Council of Canada, 2012.

21. Alderman AK, Salem B. Survey research. Plast Reconstr Surg 2010;126:1381-9. 


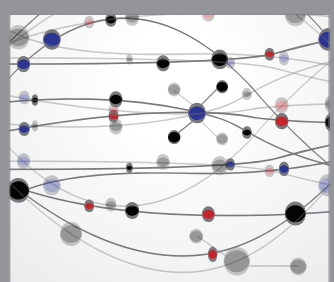

The Scientific World Journal
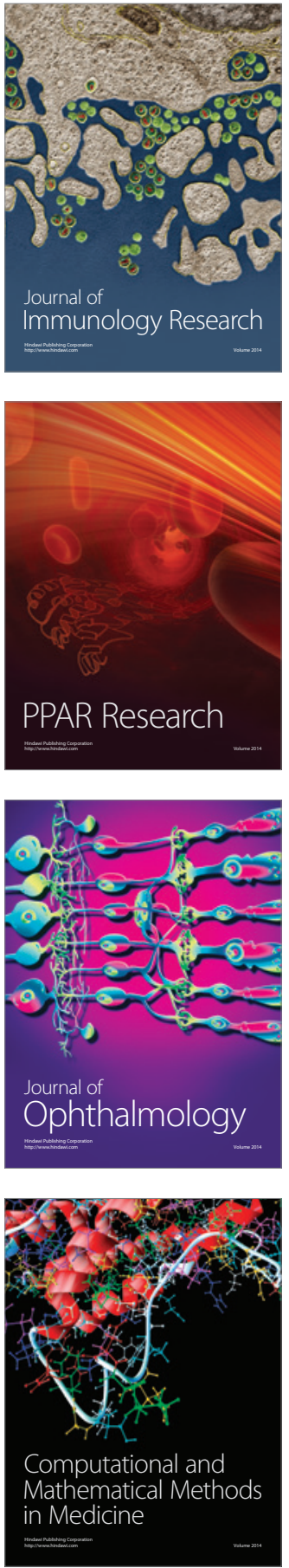

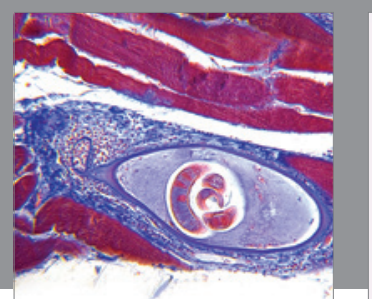

Gastroenterology Research and Practice

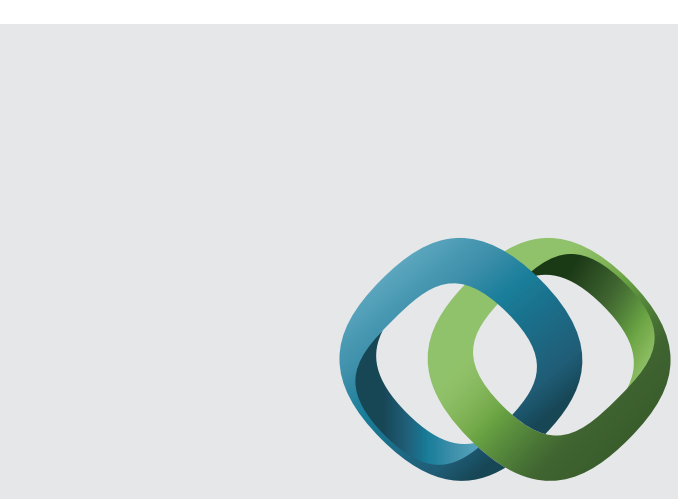

\section{Hindawi}

Submit your manuscripts at

http://www.hindawi.com
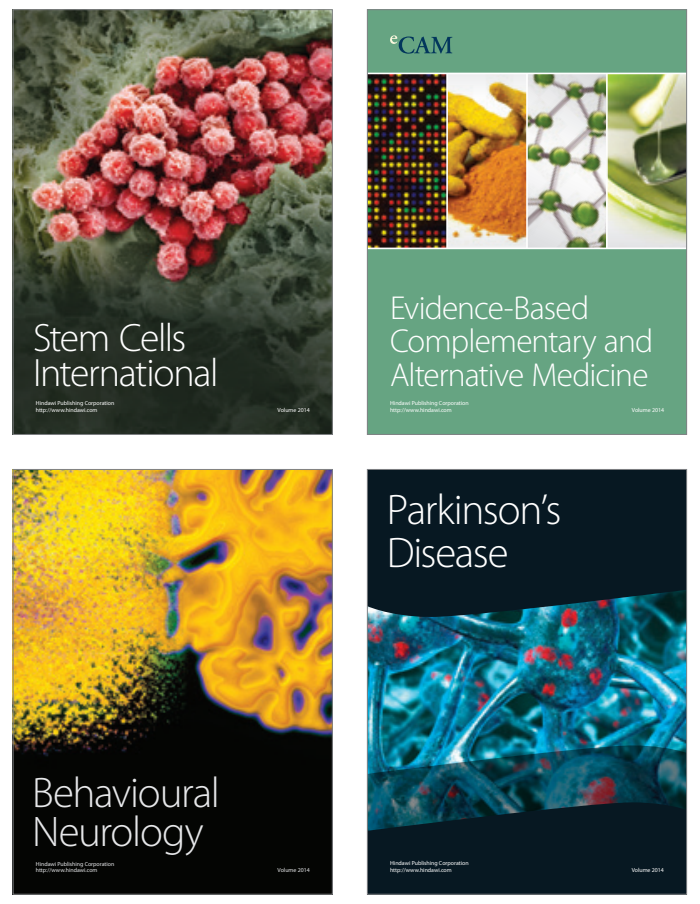
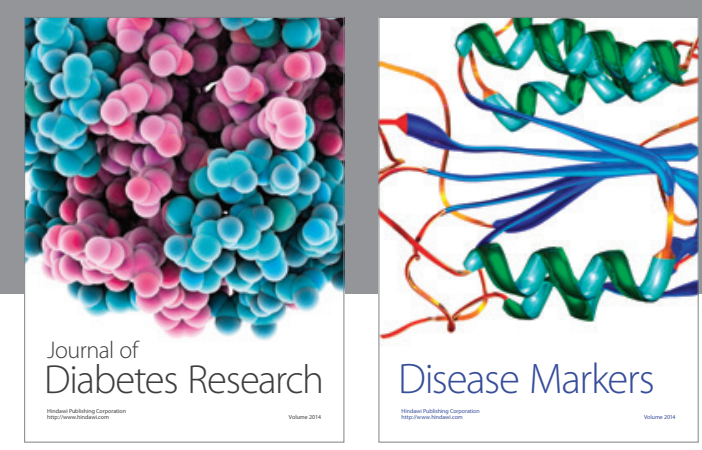

Disease Markers
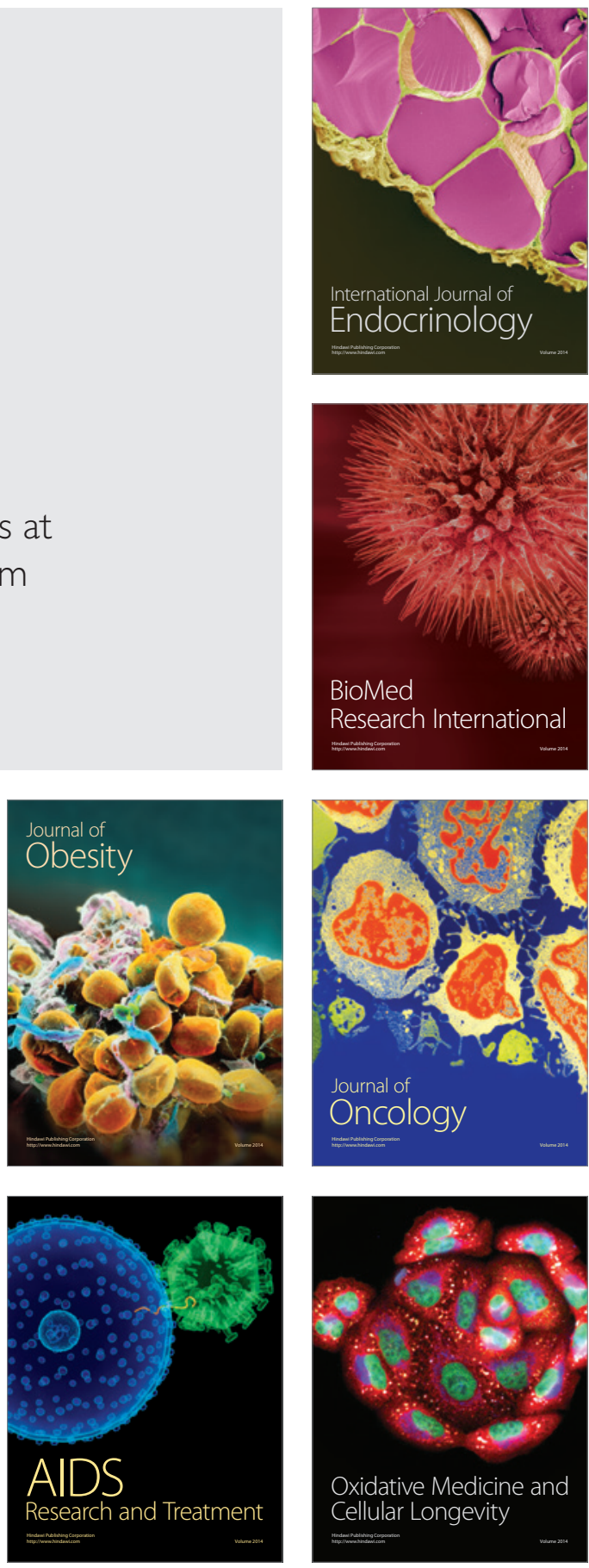